Palavras chave: Jenipapo

Banco de sementes Germinação

Histórico:

Recebido 13/07/2015 Aceito 03/03/2016

Keywords: Jenipapo Seed Bank Germination

Correspondência: francescasalla@gmail.com

\section{ANÁLISE ECOFISIOLÓGICA DE GENIPA AMERICANA L. EM BANCO DE SEMENTES INDUZIDO}

RESUMO: Este trabalho foi realizado com o objetivo de estudar o comportamento de sementes de $G$. americana L. (Rubiaceae) em bancos de sementes induzidos. A pesquisa foi realizada no município de Lavras - MG em uma floresta estacional semidecídua da Universidade Federal de Lavras. As sementes coletadas foram beneficiadas e caracterizadas quanto ao conteúdo de água, viabilidade e tolerância à dessecação. Foram instalados bancos de sementes induzidos em duas áreas distintas (topo de morro e mata ciliar) localizados no sub-bosque da floresta. As sementes foram acondicionadas em redes de náilon e cobertas com camada de serapilheira previamente removida para instalação das redes. Foi realizada avaliação mensal da germinação, emergência das plântulas, conteúdo de água das sementes e do solo e a caracterização do crescimento inicial das plântulas. Foi observado que sementes de $G$. americana formam banco de sementes transitório, com manutenção de sua viabilidade somente até o quarto mês após dispostas em ambiente natural. De modo geral, o banco de sementes na área de mata ciliar foi o que apresentou o maior potencial para o estabelecimento de plântulas em ambiente natural o que está de acordo com as características ecológicas dessa espécie.

\section{ECOPHYSIOLOGICAL ANALYSIS OF GENIPA AMERICANA L. SEEDS IN AN INDUCED SOIL SEED BANK}

ABSTRACT: This work studied the behavior of G. americana L. (Rubiaceae) seeds in an induced soil seed bank. This study was conducted in Lavras-MG in a seasonal semideciduous forest of the Federal University of Lavras. Seeds collected in the area were cleaned and analyzed (water content, viability and desiccation tolerance). Soil banks were installed in two distinct areas (top of hill and riparian forest) located in the understory of the forest. Seeds were placed in nylon nets and covered with a thin litter layer that was previously removed for this purpose. Monthly assessment of germination, seedling emergence, seed and soil water content, and the characterization of the initial seedling growth was performed. It was observed that $G$. americana seeds forms a transitory seed bank, with maintenance of its viability until the fourth month after disposal in natural environment. In general, the seed bank located in the riparian forest area showed the best potential for seedling establishment in a natural environment, which supports the ecological behavior of this species. 


\section{INTRODUÇÃO}

O conhecimento a respeito da ecologia da germinação e do crescimento de plântulas em ambiente natural é imprescindível para a compreensão dos processos comunitários de recrutamento e de sucessão e também para o desenvolvimento de estratégias de conservação da biodiversidade (KHURANA; SINGH, 200I). Ademais, estudos ecológicos direcionados a entender processos de germinação e estabelecimento de plântulas são em especial importantes para espécies que apresentam problemas no armazenamento de suas sementes, como é o caso de sementes sensíveis à dessecação (recalcitrantes e intermediárias) (ELLIS, et al., 1990; ROBERTS, 1973).

O jenipapo possui sementes classificadas como intermediárias, tolerando dessecação a baixo conteúdo de água (aproximadamente 5\%), mas não podem ser armazenadas em temperaturas negativas $\left(-20^{\circ} \mathrm{C}\right)$ (CARVALHO; NASCIMENTO, 2000). Sementes de baixa longevidade possuem diferentes estratégias de germinação e estabelecimento de plântulas. Porém, não formam bancos de sementes ou formam bancos transitórios (GARWOOD, 1989). Diante disto, mesmo sendo esses propágulos uma preocupação em programas de recuperação ambiental, devido à dificuldade na sua conservação "ex situ”, ainda são poucos os estudos que utilizam metodologia de indução de banco de sementes com sementes de baixa longevidade natural, e que, por conseguinte, formam banco de sementes transitórios. Assim, estudar o banco de sementes dessas espécies pode nos fornecer informações importantes para proceder em estratégias de conservação "in situ" adequadas para garantir o estabelecimento das plantas em áreas manejadas e/ou em vias de recuperação.

O jenipapeiro (Genipa americana L.) (Rubiaceae) é uma árvore nativa do Brasil, com altura média de 20 metros e distribuição em toda América tropical (LORENZI, 1992). É geralmente encontrada em matas mais úmidas, próximas a rios, mas pode ocorrer em matas de terra firme (SILVA et al., 2009). Possui importância econômica, pela sua madeira, casca e utilização de seus frutos na produção de alimentos (LORENZI, 1992; SILVA et al., 2009). Está sendo muito utilizada em programas de recuperação de Áreas de Reserva Legal e de Preservação Permanente (VALERI et al., 2003). Possuindo sob cultivo boas características de crescimento, produção e adaptação ecológica (SANTOS et al., 20I2).

Geralmente, em estudos de bancos de sementes, as pesquisas se direcionam ao entendimento das estratégias de regeneração das espécies através da coleta do banco de sementes no solo (WILLIAMSLINERA, 1993). Porém, induzir banco de sementes no solo pode favorecer o estudo das suas estratégias de regeneração, manutenção e estabelecimento de plântulas. Permitindo acompanhamento mais preciso das variações do conteúdo de água, viabilidade e longevidade das sementes estocadas no solo, ao longo do tempo (SRINGERNYUANG et al., 2003).

Conhecer as estratégias de germinação e estabelecimento de plântulas de espécies florestais é fundamental para o planejamento de ações de recuperação e de estratégias de conservação e preservação, além de significativos para o entendimento e condução da regeneração em florestas sob o regime de algum tipo de manejo (VENTUROLI, et al., 2007). Diante deste contexto, o objetivo nesta pesquisa foi estudar o banco de sementes de Genipa americana L. (Rubiaceae) em dois ambientes florestais.

\section{MATERIAL E MÉTODOS}

\section{Área de estudo}

estudo foi conduzido em áreas experimentais da Universidade Federal de Lavras (UFLA), município de Lavras - MG e no Laboratório de Semente Florestais (LSF) do Departamento de Ciências Florestais da UFLA. Foi selecionada uma área situada em topografia elevada denominada topo de morro (2/ㅇ 3.690' S 44ํ58.223' W, 912 m de altitude) e outra localizada em área de baixada caracterizada como mata ciliar (área com influência do lençol freático e do curso d'água) (2/ㅇ․836’ $\mathrm{S}$ 4458.793' W, $892 \mathrm{~m}$ de altitude), para instalação do banco de sementes induzido no solo.

\section{Seleção de matrizes, coleta e beneficiamento das sementes}

Foram selecionadas para o estudo sete matrizes de jenipapo. Estas foram visitadas periodicamente para determinar o ponto de maturidade dos frutos. A coleta foi realizada diariamente nos meses de maio e junho de 2013 , durante a estação seca.

Os frutos foram despolpados manualmente e as sementes lavadas com areia em peneira de malha fina, de forma que apenas parte da mucilagem existente nas sementes fosse retirada. Posteriormente estas passaram por secagem, em laboratório, para eliminar a umidade superficial e foram armazenadas em câmara fria (5 \pm 2 ${ }^{\circ} \mathrm{C}$ e UR $60 \%$ ) em embalagem semipermeável por, no máximo, sete dias. 


\section{Caracterização inicial do lote de sementes}

O conteúdo de água foi determinado utilizando-se o peso úmido (em sementes frescas) e o peso seco (em sementes secas em estufa a $105 \pm 3^{\circ} \mathrm{C}$ por 24 horas) de quatro amostras de cinco sementes cada (Equação I). Utilizou-se a fórmula de determinação do conteúdo de água (base úmida).

Conteúdo de água $=\left((\right.$ Peso úmido-Peso seco $\left.) \cdot(\text { Peso úmido })^{-1}\right) \cdot 100[\mathrm{I}]$

O teste de germinação foi realizado com quatro repetições de 25 sementes, utilizando-se placas de Petri contendo duas folhas de papel filtro como substrato. $O$ experimento foi conduzido em câmara de germinação a $25^{\circ} \mathrm{C}$ com luz constante e as avaliações ocorreram diariamente. Foi utilizado como critério de germinação a protrusão da radícula $(\geq 2,0 \mathrm{~mm})$.

\section{Curva de secagem}

Para a caracterização da tolerância à dessecação, as sementes foram submetidas à secagem em diferentes conteúdos de água $(30,20,15,10$ e 5\%). A secagem foi realizada em recipiente contendo solução saturada de cloreto de sódio para o controle da umidade relativa do ar a $\left(76 \%\right.$ a $\left.20^{\circ} \mathrm{C}\right)$. Quando não foi mais possível à diminuição do conteúdo de água nessas condições, a solução saturada de $\mathrm{NaCl}$ foi substituída por sílica gel ativada. $\mathrm{O}$ conteúdo de água das sementes durante a secagem foi estimado através da equação 2 proposta por Hong e Ellis (1996). Em que: Mi: massa (g) no conteúdo de água inicial; CAi: conteúdo de água inicial (\% base úmida); CAd: conteúdo de água desejado (\% base úmida).

Massa do conteúdo de água desejado $(\mathrm{g})=\left(\left((100-\mathrm{CAi}) \cdot(100-\mathrm{CAd})^{-1}\right) \cdot \mathrm{Mi}\right) \quad$ [2]

As amostras foram pesadas até que o conteúdo de água nos pontos de interesse fosse alcançado. Em seguida, realizou-se teste de germinação.

\section{Banco de sementes induzido}

Após a caracterização do lote, realizou-se a instalação do banco de sementes nas áreas de topo de morro e mata ciliar. Para isto, as sementes foram acondicionas em redes de náilon, abertas na superfície, em quatro repetições de 200 sementes cada. As sementes foram distribuídas uniformemente nas redes sobre o solo e cobertas com camada de serrapilheira previamente removida para instalação das redes. Foi realizada avaliação mensal da germinação através das plântulas emergidas da camada vegetal.

Também foram alocadas, 18 amostras contendo 250 sementes cada. As sementes foram distribuídas de forma homogênea, dentro de redes de náilon e cobertas por aproximadamente $3 \mathrm{~cm}$ de serrapilheira. Cada amostra foi individualizada para retirada mensal em cada ambiente. Propiciando determinação do conteúdo de água, número de sementes germinadas (protrusão radicular), viáveis (não germinadas) e mortas ao longo do tempo.

Foram retirados os embrióes das sementes não germinadas e estes colocados em recipientes contendo solução de $1 \%$ de tetrazólio, por 24 horas em câmara B.O.D. a $20^{\circ} \mathrm{C}$. Embriões que não possuíam coloração vermelha em suas partes vitais foram considerados mortos. Enquanto embriões com mais de $75 \%$ de coloração vermelha (já sendo considerado o local de coloração) foram considerados viáveis. Ao longo dos meses, amostras de solo foram retiradas aleatoriamente nas duas áreas florestais para a determinação do seu grau de umidade, que seguiu metodologia proposta pela EMBRAPA (1997).

Todos os experimentos foram montados em delineamento inteiramente casualizado (DIC). Foi realizada análise descritiva do comportamento das sementes ao longo do tempo.

\section{RESULTADOS E DISCUSSÃO}

Assementes de Genipa americana, logo após a coleta, apresentaram conteúdo de água de $56 \%$ e germinação de $94 \%$. A secagem das sementes a 30 e $20 \%$ de conteúdo de água apresentou pouco efeito sobre a germinação, entretanto, quando o conteúdo de água foi reduzido para 15,10 e $5 \%$ observou-se redução na viabilidade das sementes para $58,4 \mathrm{le}$ 1\%, respectivamente (Figura I).

Os resultados deste estudo são semelhantes aos de Oliveira et al. (20I I), que também mostrou redução da viabilidade quando as sementes foram secas próximas a I $5 \%$ do conteúdo de água. Entretanto, esses resultados contrastam com os descritos por Carvalho e Nascimento

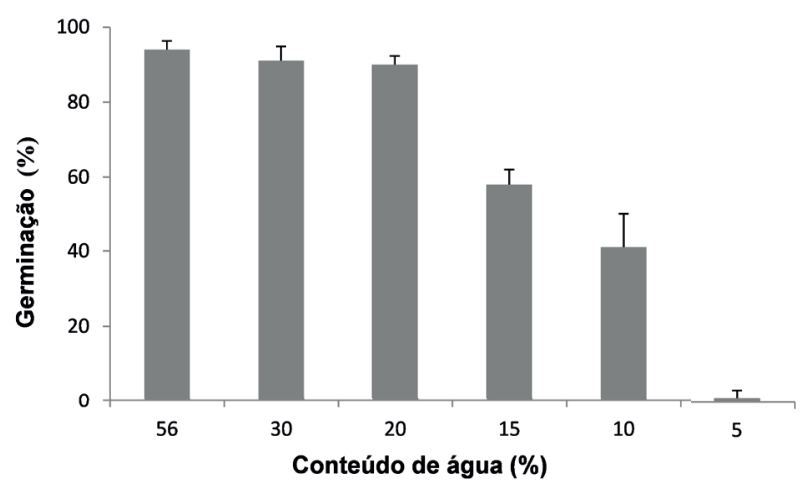

FIGURA 1 Efeito da secagem na germinação de sementes de Genipa americana.

FIGURE 1 Drying effect on seed germination of Genipa americana. 
(2000), Magistrali et al. (2013) e Salomão (2004), que observaram a redução na longevidade somente quando as sementes foram secas abaixo de $10 \%$ do conteúdo de água.

Ao longo do ano o conteúdo de água do solo no ambiente de topo de morro apresentou menor variação e valores ligeiramente superiores quando comparados aos do solo da mata ciliar (Figura 2). Porém, as sementes na mata ciliar, ao longo do tempo, apresentaram conteúdo de água superior àquelas que se encontravam na mata de topo de morro.

Por estarem em ambientes diferentes (topo de morro e mata ciliar) as sementes estavam dispostas a características ambientais distintas. A mata ciliar possuía maior luminosidade decorrente da proximidade em que - experimento estava da borda da floresta (próximo ao lago). Estando, portanto, passível as influências dos reconhecidos efeitos de borda.

Entre os ambientes, além das diferenças de luminosidade observou-se diferenças na coloração e textura dos dois solos. Espirito-Santo et al. (2002) classificaram os tipos de solos existentes em um fragmentos da floresta estacional semidecídua da Universidade Federal de Lavras, abrangendo áreas baixas e alta encosta do fragmento. Seus resultados verificaram diferentes tipos de solos nessas áreas, com características distintas relacionadas à porcentagem de matéria orgânica, silte, argila, areia, $\mathrm{pH}$ e status nutricional. A proporção desses componentes no solo da mata ciliar, provavelmente pode ter provocado aumento da taxa de infiltração da água, e em conjunto com maior incidência solar, aumento da evaporação da água do solo. Passando este ambiente a apresentar menor conteúdo de água no solo quando comparado à mata de terra firme.

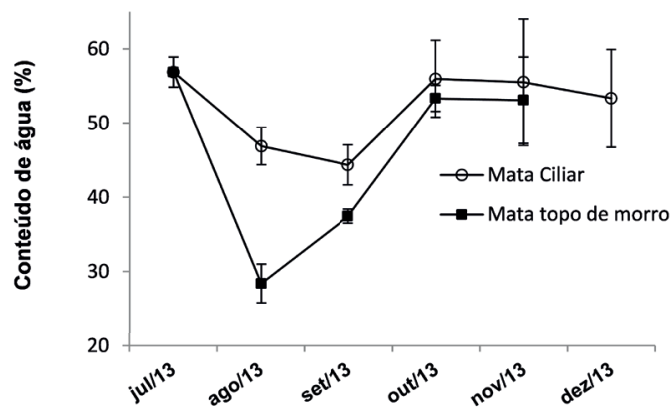

A disponibilidade de água para as sementes depende também do potencial das zonas que estão em seu entorno bem como a velocidade em que a água se move através do solo garantindo uma condutividade hidráulica adequada. A semente pode ainda absorver água através da fase de vapor, mediante as taxas de difusão de gás nos espaços do solo, não sendo limitada, portanto, unicamente pela condutividade hidráulica (BEWLEY, et al., 20/3). Assim, são vários os fatores que podem estar influenciando as diferenças de conteúdo de água das sementes nos dois ambientes florestais.

No primeiro mês após a implantação do banco de sementes, as sementes mantidas na mata ciliar apresentaram redução de apenas $10 \%$ no conteúdo de água das sementes, correspondendo a $48 \%$ de conteúdo de água, enquanto que naquelas alocadas no topo de morro essa redução foi mais pronunciada (29\%), com sementes possuindo em torno de $28 \%$ de conteúdo de água. Entretanto, em nenhum desses locais o conteúdo de água das sementes ficou abaixo do valor crítico, visto que somente abaixo de $20 \%$ (Figura I) foram observados efeitos negativos da secagem.

Após um mês expostas no ambiente (agosto), verificou-se em ambos os ambientes redução de $31 \%$ na viabilidade das sementes. A partir de agosto, o ambiente de topo de morro apresentou as maiores porcentagens de sementes viáveis, com cerca de $60 \%$ em setembro e redução para $30 \%$ em outubro. Enquanto na mata ciliar a porcentagem de sementes viáveis em setembro foi de $26 \%$ com redução no mês de outubro para $20 \%$ (Figura 3). Contudo, independente do ambiente em que as sementes de Genipa americana foram dispostas, verificou-se que a sua viabilidade se manteve somente até o quarto mês de avaliação (novembro).

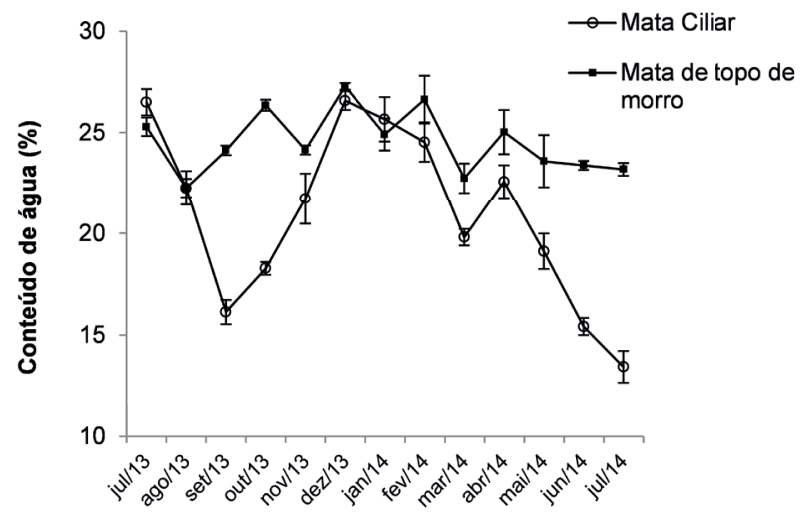

FIGURA 2 Variação do conteúdo de água do solo e das sementes nos ambientes mata ciliar e topo de morro no período de julho/2013 a julho/2014. As barras representam o desvio padrão.

FIGURE 2 Soil and seed moisture content variation in riparian environments and hill top from July/2013 to July/2014. The bars represent the standard deviation. 

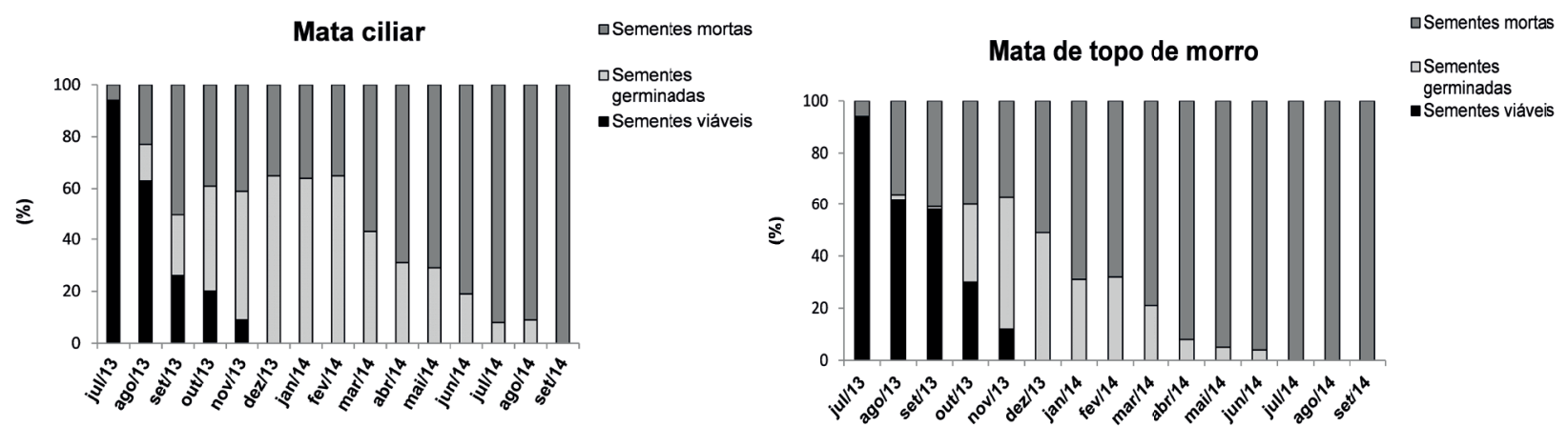

FIGURA 3 Viabilidade de sementes de Genipa americana em bancos de sementes induzidos em duas áreas (Mata ciliar e Mata de topo de morro) entre os meses de julho e dezembro de 2013.

FIGURE 3 Seed viability of Genipa americana in seed induced banks on two areas (Riparian forest and hill top) Forest between July and December 2013.

Embora em baixas porcentagens, a germinação, em ambos os ambientes, ocorreu logo após as sementes estarem dispostas em ambiente natural. Observou-se a tendência de aumento da germinação compreendida entre os períodos de agosto a dezembro de 2013, relacionando-se ao período de aumento das precipitações na região. No entanto, na floresta de topo de morro, as porcentagens de germinação em agosto $(2,6 \%)$ e setembro $(1,4 \%)$ foram menores quando comparadas aos valores da mata ciliar que apresentou $14 \%$ de germinação em agosto e $24 \%$ em setembro.

Maior porcentual germinativo na mata ciliar pode ser observado ao longo de todo o período avaliado (agosto/2013 a agosto/2014), com exceção apenas para o mês de novembro de 2013, no qual para ambos os ambientes observou-se em torno de $60 \%$ de germinação. Pode-se observar ainda que na mata ciliar o número de sementes germinadas possui pouca variação até fevereiro de 2014, quando começa a decrescer, enquanto que na área de topo de morro essa redução tem início em dezembro de 2013.

No geral, observou-se nos primeiros meses avaliados (agosto a novembro de 2013) baixa variação na mortalidade de sementes, com aumento a partir de novembro de 2013 na mata de topo de morro e apenas a partir de março de 2014 na mata ciliar (Figura 3).

A germinação verificada logo após as sementes estarem dispostas em ambiente natural pode ter ocorrido devido ao alto conteúdo de água inicial em que estas foram levadas a campo (aproximadamente $56 \%$ ), bem como pela alta umidade do solo (acima de 20\%). Segundo (BEWLEY et al., 2013), conteúdos de água acima de $50 \%$ já podem promover divisão celular, germinação e crescimento. Dessa forma, provavelmente, parte das sementes que foram dispostas no campo já se encontravam suficientemente hidratadas para ativação da atividade metabólica, aumentando a respiração, síntese proteica e de ácidos nucleicos.

As diferenças na viabilidade das sementes entre os ambientes estudados foram determinadas provavelmente pelas diferenças existentes entre eles. Segundo Fenner e Thompson (2005), as condições microambientais podem variar significativamente de um ponto para outro dentro de um mesmo ambiente florestal. Assim, variações em iluminação, umidade e temperatura (FENNER; THOMPSON, 2005; SRINGERNYUANG et al., 2003; YU et al., 2008) podem ocorrer em maior ou menor intensidade entre ambientes florestais distintos, interferindo no comportamento germinativo de sementes de algumas espécies.

Em ambos os ambientes, a germinação do banco de sementes induzido teve início logo após dispostas em ambiente natural. Porém, na mata de topo de morro, a emergência (hipocótilo com cotilédones contidos no tegumento) ocorreu ao longo de cinco meses, iniciandose em outubro de 2013 com apenas $2,7 \%$, elevando-se para $18,3 \%$ em novembro e seguida de redução nos meses posteriores. Já na mata ciliar, a emergência foi observada ao longo de sete meses, verificando no mês de outubro $5 \%$ de emergência, pico de germinação no mês de novembro (16,5\%) e redução do número de plântulas emergentes nos meses posteriores. Verificando em todos os meses maior porcentagem de plântulas neste ambiente (Figura 4).

Neste estudo, na mata de topo de morro as folhas cotiledonares iniciaram sua abertura no segundo mês (novembro) após a emergência, ou seja, quatro meses após a semeadura, crescendo o número de plântulas com folhas cotiledonares nos três meses seguintes. O primeiro par de folhas surgiu seis meses após a emergência, correspondendo a $13,4 \%$ das amostras. 

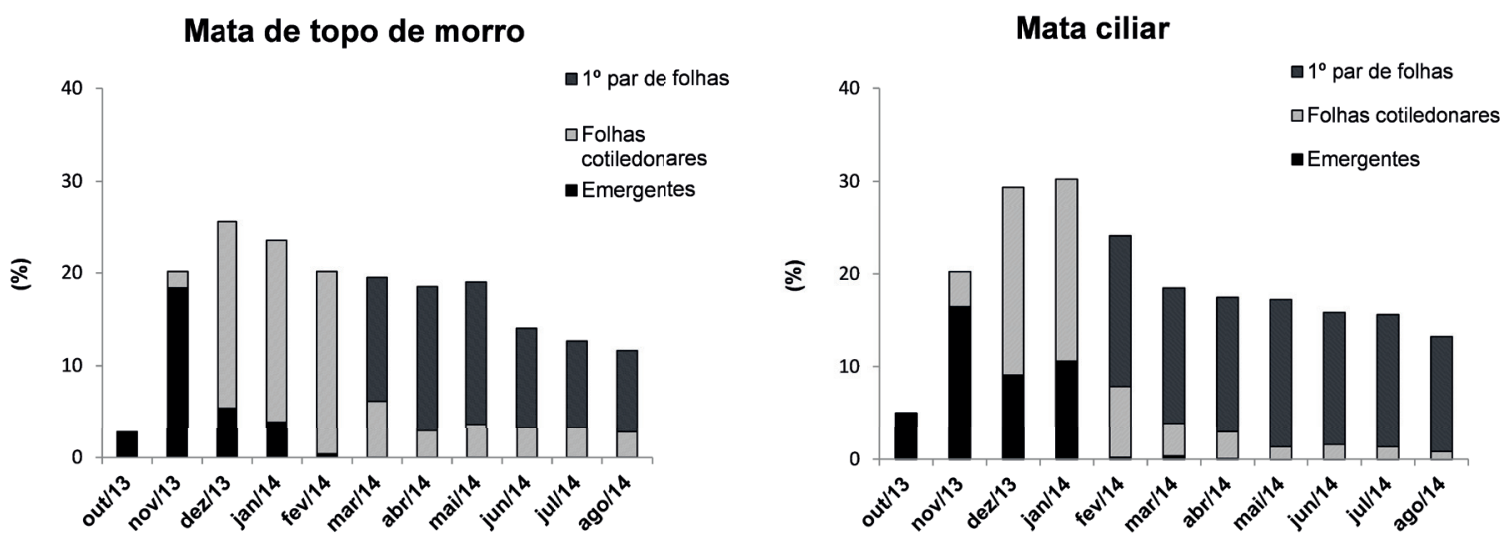

FIGURA 4 Emergência e estabelecimento de plântulas em dois ambientes florestais distintos, topo de morro (A), mata ciliar (B) de uma floresta estacional semidecidual do município de Lavras, MG.

FIGURE 4 Seedling emergence and establishment on two different forest hill top (A) and riparian (B) from a semi-deciduous forest in the city of Lavras, MG.

A partir de julho, houve queda do número de plântulas estabelecidas com o primeiro par de folhas.

$\mathrm{Na}$ mata ciliar, a proporção de plântulas com cotilédones abertos correspondeu a $3,8 \%$, seguida de aumento no mês de dezembro e janeiro e decrescendo a partir de então. As primeiras folhas tiveram sua abertura um mês antes das amostras do topo de morro, com valores variando entre 16\% (março/2013) e I2\% (agosto/20|4).

O comportamento das sementes de $G$. americana que foram induzidas no banco de sementes adequou-se ao modelo definido por Garwood (1996), como um banco de sementes transitório, de forma que aos sete meses no ambiente de mata ciliar e cinco meses no ambiente topo de morro, ainda havia emergência de plântulas, mas após esse período todo o banco de sementes foi substituído pelo banco de plântulas.

Alguns autores têm verificado o aparecimento da plântula na superfície do solo (emergência) como o primeiro sinal que efetiva a germinação (GONZÁLEZ-ZERTUCHE et al., 200 I; YU et al., 2008). Neste estudo, em ambiente de mata ciliar, somente $30 \%$ das amostras de sementes do banco induzido apresentaram sucesso na emergência (Figura 4), verificando-se alta mortalidade entre a protrusão da radícula e a emergência em ambos ambientes.

Segundo Fenner e Thompson (2005) as chances de sucesso no estabelecimento de plântulas podem ser influenciadas de acordo com o grau de sombreamento da vegetação circundante. Genipa americana é considerada uma espécie tolerante à sombra do grupo das secundárias iniciais, ela encontra-se em ambientes de sombreamento médio e luminosidade não muito intensa (LIMA, APARICIO; SILVA, 20I4). Ambos ambientes (terra firme e mata ciliar) apresentavam estrutura da vegetação adequada a germinação e desenvolvimento de plântulas desta espécie. Porém, diferenças nos resultados encontrados na mata ciliar podem estar sendo influenciados pelo reconhecidos efeito de borda, em especial referentes à maior radiação solar, típico desses ambientes (MURCIA, 1995).

Garwood (1996) determina cinco fases ontogenéticas em espécies lenhosas tropicais. Sendo a fase I (semente); fase 2 de alongamento da plântula que ocorre logo que se verifica a germinação e termina com a emissão do primeiro tecido fotossintetizante; fase 3 que se caracteriza pela utilização dos tecidos fotossintetizantes, em casos em que a plântula já utilizou totalmente as reservas contida na semente; fase 4 , chamada de juvenil em que as plântulas não utilizam mais as reservas dos cotilédones e a fase 5 , adulto. Assim, observando o comportamento das sementes de G. americana ao longo do tempo, verifica-se que as fases I e 2 ocorrem desde a germinação (sob camada de serrapilheira e não visualizada neste estudo), continua com emergência dos cotilédones acima da serrapilheira, sendo que no caso desta espécie, os cotilédones ainda encontram-se dentro do tegumento das sementes (fase 2) e termina com a exposição dos cotilédones ao ambiente. Nesse momento, as sementes passam a ser reconhecidas estando na fase 3, provavelmente apresentando cotilédones fotossintetizantes. Conforme aferido neste trabalho, a fase 3 das sementes de $G$. americana dura pelo menos três meses antes que $\circ$ primeiro par de folhas se desenvolva e esta passe a ser independente dos cotilédones, determinando a fase juvenil. As verificações 
morfológicas verificadas neste estudo não possibilitaram a identificação da fase 5 (adulto).

Segundo Andrade et al. (2000), a classificação mais adequada para a espécie $G$. americana seria a proposta por Duke e Polhill (198I), em que a germinação é considerada faneroepígea, com características de acordo com as citadas acima e, ainda, por serem dependentes dos cotilédones até que ocorra o surgimento das primeiras folhas. Segundo Fenner e Thompson (2005), o último estádio no processo de regeneração é indicado como o estabelecimento de plântulas no interior das florestas.

\section{CONCLUSÕES}

Sementes de Genipa americana possuem banco de sementes transitórios com sementes viáveis somente até o quarto mês pós-dispersão. Após os eventos germinativos, as plântulas desta espécie se mantêm em desenvolvimento por um período superior a dez meses, quando ocorre o surgimento do primeiro par de folhas. Isso implica em estratégias diferenciadas em programas de recuperação, conservação e introdução de G. americana, e outras espécies que apresentam características semelhantes, em ambientes naturais. Uma vez que as estratégias de regeneração devem estar atreladas, em especial, ao banco de plântulas formado no interior da floresta.

\section{REFERÊNCIAS}

ANDRADE, A. C. S. de et al. Germinação de sementes de jenipapo: temperatura, substrato e morfologia do desenvolvimento pós-seminal. Pesquisa Agropecuária Brasileira, Brasileira, v. 35, n. 3, p. 609-6I5, mar. 2000.

BEWLEY, J. D.; BRADFORD, K. J.; HILHORST, H. W. M.; NONOGAKI, H. Seeds: physiology of development, germination and dormancy. 3rd ed. New York: SpringerVerlag, 2013. 376 p.

CARVALHO, J. E. U.; NASCIMENTO, W. M. O. Sensibilidade de sementes de jenipapo (Genipa americana L.) ao dessecamento e ao congelamento. Revista Brasileira de Fruticultura, Jabotical, v. 22, n. I, p. 53-56, abr. 2000.

DUKE, J. A.; POLHILL, R. M. Seedlings of Leguminosae. In: POLHILL, R. M.; RAVEN, P. H. (Ed.). Advances in legume systematics. Kew: Royal Botanical Gardens, I98I. v. 2, p. 94I-949.

ELLIS, R. H.; HONG, B.; ROBERTS, E. H. An intermediate category of seed storage behavior? Journal of Experimental Botany, Oxford, v. 4I, n. 9, p. I I67-I I74, Sept. 1990.

EMPRESA BRASILEIRA DE PESQUISA AGROPECUÁRIA. Manual de métodos de análise de solo. Brasília: Centro Nacional de Pesquisa de Solos, 1997. 212 p.
ESPIRITO-SANTO, F. D. B.; OLIVEIRA-FILHO, A. T. de; MACHADO, E. L. M.; SOUZA, J. S.; FONTES, M. A. L.; MARQUES, J. J. de S. e M. variáveis ambientais e a distribuição de espécies arbóreas em um remanescente de floresta estacional semidecídua montana no campus da Universidade Federal de Lavras, MG. Acta Botanica. Brasilica v. 16, n. 3, p. 33I-356, 2002.

FENNER M.; THOMPSON, K. The ecology of seeds. Cambridge: University Press, 2005. 250 p. GARWOOD, N. C. Functional morphology of tropical tree seedlings. In: SWAINE, M. D. (Ed.). The ecology of tropical forest tree seedlings. Paris: UNESCO/Parthenon, 1996.p.59-129.

GARWOOD, N. C. Tropical soil seed banks: a review. In: LECK, M.; PARKER, V.; SIMPSON, R. (Ed.). Ecology of soil seed banks. San Diego: Academic Press, 1989. chap. 9, p. I49-209.

GONZÁLEZ-ZERTUCHE, L.; VÁZQUEZ-YANES, C.; GAMBOA, A.; SÁNCHEZ-CORONADO, M. E.; AGUILERA, P.; OROZCO-SEGOVI, A. Natural priming of Wigandia urens seeds during burial: effects on germination, growth and protein expression. Seed Science Research, n. II, p. 27-34, 200I.

KHURANA, E.; SINGH, J. S. Ecology of tree seed and seedlings: implications for tropical forest conservation and restoration. Current Science, Bangalore, v.80, n.6, p. 748-757, Mar. 200 I.

LIMA, R. C.; APARICIO P. DA S.; SILVA, W. C. da. Classificação ecológica de uma floresta de várzea submetida à ação antrópica. Revista de Ciências da Amazônia, n. 2, v. 2, p. 9-19, 2014.

LORENZI, H. Árvores brasileiras: manual de identificação e cultivo de plantas arbóreas nativas do Brasil. Nova Odessa: Plantarum, 1992. 368 p.

MAGISTRALI, P. R. et al. Physiological behavior of Genipa americana $L$. seeds regarding the capacity for desiccation and storage tolerance. Journal of Seed Science, Londrina, v. 35, n. 4 , p. $495-500,2013$.

MURCIA, C. 1995. Edge effects in fragmented forests: implications for conservation. Trends in Ecology and Evolution, n. 10, p. 58-62, 1995.

OLIVEIRA, L. M.; SILVA, E. O.; BRUNO, R. L. A.; ALVES, E. $U$. Períodos e ambientes de secagem na qualidade de sementes de Genipa americana L. Semina: Ciências Agrárias, Londrina, v. 32, n. 2, p. 495-502, abr./jun. $201 \mathrm{I}$.

ROBERTS, E. H. Predicting the storage life of seeds. Seed Science and Technology, Zürich, v. I, n. 3, p. 499-5I4, 1973.

SALOMÃO, A. N. Desiccation, storage and germination of Genipa americana seeds. In: SACANDÉ, M.; JOKER, D; DULLOU , M. E.; Thomsen, K. A. (Ed.). Comparative storage: biology of tropical tree seeds. Rome: IPGRI, 2004. p. 263-269. 
SANTOS, S. C.; BUDKE, J. C; MULLER, A. Regeneração de espécies arbóreas sob a influência de Merostachys multiramea Hack.(Poaceae) em uma floresta subtropical. Acta Botanica Brasilica, Feira de Santana, v.26, n. I, p. 218-229, jan./mar.20I2.

SILVA, A. V. C. da et al. Caracterização físico-química de jenipapo. Aracaju: EMBRAPA, 2009. 4 p.(EMBRAPA. Comunicado técnico, 99).

SRI-NGERNYUANG, K. et al. Survival and germination of an experimental seed bank population of two species of Lauraceae in a tropical montane forest in Thailand. Journal of Forest Research, Tokyo, v. 8, n. 4, p. 3।I-3।6, Nov.2003.
VALERI, S. V.; PUERTA, R.; CRUZ, M. C. P. da. Efeitos do fósforo do solo no desenvolvimento inicial de Genipa americana L. Scientia Forestalis, Piracicaba, n. 64, p. 69-67, dez. 2003.

VENTUROLI, F.; FELFILI, J.; FAGG, C. W. Dinâmica de regeneração natural em capoeira de floresta estacional semidecidual sob manejo florestal de baixo impacto. Revista Brasileira de Biociências, Porto Alegre, v. 5, p. 435-437, jul. 2007. Suplemento I.

WILLIAMS-LINERA, G. Soil seed banks in four lower montane forests of Mexico. Journal of Tropical Ecology, Cambridge, v. 9, n. 3, p. 321-337, Aug. 1993.

YU, Y. et al. Ecology of seed germination of eight non-pioneer tree species from a tropical seasonal rain forest in southwest China. Plant Ecology, v. I97, n. I, p. I-16, July 2008. 